\author{
毛利誠・佐藤 紀夫・岡本 浩孝・松下 光正 \\ 本多 秀亘・中島 克己・竹内 勝政 \\ 鈴木 康之・大脇 雅夫
}

\title{
CONTINUOUS DEVULCANIZATION BY SHEAR FLOW STAGE REACTION CONTROL TECHNOLOGY FOR RUBBER RECY- CLING, PART 5. DEVULCANIZATION CONDITION AND MECHANICAL PROPERTIES OF REVULCANIZED RUBBER FOR USED TIRE WASTE
}

Makoto MOURI, Norio SATO, Hirotaka OKAMOTO, Mitsumasa MATSUSHITA (TOYOTA CENTRAL R\&D LABS., INC., 41-1, Aza yokomichi, Oaza Nagakute, Nagakute-cho, Aichi-gun, Aichi 480-1192 JAPAN)

Hidenobu HONDA, Katsumi NAKASHIMA, Katsumasa TAKEUCHI (TOYODA GOSEI Co. LTD. , 30, Nishinomachi, Kitajima-cho, Inazawa- city, Aichi, 492-8411 JAPAN) Yasuyuki SUZUKI, Masao OWAKI (TOYOTA MOTOR CORPORATION, 1, Toyota-cho, Toyota-city, Aichi, 471-8572 JAPAN)

Continuous devulcanization by shear flow stage reaction control technology for sulfur vulcanized EPDM rubber has been developed. In this study, this technology has been applied for the devulcanization of rubber tire consisting of NR/SBR which has been used in practice. By optimizing devulcanization conditions such as reaction temperature, screw rotation and addition of process oil, devulcanized rubber can be extruded continuously. The devulcanized rubber can be revulcanized by conventional curing process with sulfur-accelerator vulcanizing system. The revulcanized rubber shows good mechanical properties which meet JIS K6313 standard.

(Received on July 31, 1998)

Key Word : Recycle, Vulcanized rubber, Shear flow stage reaction control technology, Devulcanization, NR/SBR, Used tire waste

\section{1. 緒言}

ゴム再生技術として，せん断流動場反応制御技 術により加硫ゴムを短時間で連続的に再生する技 †本報を「せん断流動場反応制御技術によるゴムの連続再 生 (第 5 報)」とする.
術を提案し，先にその技術の概要について報告し $た^{1-4)}$. 本技術では，せん断流動場反応槽を用い た脱硫反応処理において，ゴムの硫黄架橋点を選 択的に切断することにより，高品位な再生ゴムを 連続的に得ることが可能となった. 硫黄加硫 EPDM を対象に脱硫反応処理を行った場合，ス 
Table 1 Composition of used tire waste

\begin{tabular}{lr}
\hline Ingredients & $\%$ \\
\hline Aceton extract & 8 \\
Carbon black & 30 \\
Ash & 6 \\
\hline
\end{tabular}

Table 2 Compounding recipe of devulcanized rubber

\begin{tabular}{lr}
\hline Ingredients & phc \\
\hline Devulcanized rubber & 100 \\
Zinc oxide & 1.25 \\
Stearic acid & 0.25 \\
Sulfur & 0.75 \\
CBS & 0.25 \\
\hline
\end{tabular}

CBS : N-Cyclohexyl-2-benzothiazolylsulfenamide

クリュ形状, 処理温度, スクリュ回転数を適切に 設定することにより, 分解剂/再生オイルを添加 しなくても脱硫反応処理が可能であり，得られる 再生ゴムの成形性, 加硫特性および力学特性は新 材とほぼ同等となった。

次に本技術の適用範囲を拡大するために，廃夕 イヤ $(\mathrm{NR} / \mathrm{SBR})$ を対象に脱硫反応処理の検討を 行った，本報では，種々検討の結果，廃夕イヤを 対象とした場合でも本手法の有効性が確認できた ので，その結果について報告する。

\section{2. 実験}

\section{1 材 料}

実験にはバス・トラック用タイヤの使用済み廃

Table 3 Mechanical properties of revulcanized rubber

\begin{tabular}{cccccc}
\hline & Condition & & \multicolumn{2}{c}{$\begin{array}{c}\text { Mechanical properties } \\
\text { of revulcanized rubber }\end{array}$} \\
\cline { 1 - 1 } \cline { 5 - 5 } $\begin{array}{c}\text { Amount of } \\
\text { reclaiming oil } \\
(\mathrm{phc})\end{array}$ & $\begin{array}{c}\text { Temperature } \\
\left({ }^{\circ} \mathrm{C}\right)\end{array}$ & $\begin{array}{c}\text { Screw rotation } \\
(\mathrm{rpm})\end{array}$ & $\begin{array}{c}\text { Tensile } \\
\text { strength } \\
(\mathrm{MPa})\end{array}$ & $\begin{array}{c}\text { Elongation } \\
\text { at break } \\
(\%)\end{array}$ \\
\hline 10 & 200 & 200 & 12.0 & 340 \\
10 & 240 & 100 & 10.5 & 330 \\
10 & 240 & 200 & 9.4 & 330 \\
10 & 240 & 400 & 6.6 & 300 \\
10 & 260 & 200 & 6.0 & 270 \\
10 & 280 & 200 & 4.0 & 220 \\
0 & 240 & 200 & 7.5 & 200 \\
\hline
\end{tabular}

材を用いた. NR と SBR のブレンド比は約 7 対 3 である.夕イヤに含まれている繊維および金属 は粉砕の際に取り除いた。また，試料の組成は JIS K 6350 に準拠して分析した. その結果を Table 1 に示す. 脱硫実験には粉砕した試料およ びこの試料にプロセスオイルを 10 重量部添加し たものを用いた。

\section{2 せん断流動場反応槽による脱硫反応処理}

脱硫反応処理には前報 ${ }^{2)}$ と同様の二軸スクリュ からなる連続処理方式のせん断流動場反応槽を用 いた。 上記試料を，せん断流動場反応槽に $5 \mathrm{~kg} /$ hの一定速度で供給し, 混練しながら脱硫反応を 行い再生ゴムを得た。実験機を用いた処理では， 処理温度(ゴム温度)が $170 \sim 320^{\circ} \mathrm{C}$ ，スクリ工回 転数が $100 \sim 400 \mathrm{rpm}$ の範囲で検討を行い, 最適 条件を求めた。

\section{3 再生ゴムの評価}

再生ゴムのムーニ一粘度, ゲル成分量, ゲル成 分の有効網目鎖濃度, ゾル成分の分子量分布を前 報2)と同様の手法により測定した。

\section{4 再加硫ゴムの評価}

JIS K 6313 に準拠して再生ゴムに Table 2 の 配合で硫黄と加硫促進剂を添加し， $141^{\circ} \mathrm{C} て ゙ 20$ 分 間プレス加硫して再加硫ゴムを得た。加硫特性は キュラストメーターを用いて， $141^{\circ} \mathrm{C} て ゙$ 評価した。 再加硫ゴムの有効網目鎖濃度, 引張強さ, 破断伸 びは前報2)と同様の手法により測定した。

\section{3 ．結果および考察}

\section{1 再生ゴムの特性}

再加硫ゴムの引張強さ，破断伸びを評価基準と

して, せん断流動場反応槽の処理 温度，スクリュ回転数およびプロ セスオイルの添加の有無を種々検 討した．各処理条件における再加 硫ゴムの力学特性を Table 3 に 示す。その結果，試料にプロセス オイルを添加し, 処理温度が $200^{\circ} \mathrm{C}$ ，スクリュ回転数が 200 rpmでの処理が最適であり，得 られる再加硫ゴムの力学特性は最 大となった。この条件で得られる 再生ゴムのムーニ一粘度, ゲル成 分量, ゲル成分の有効網目鎖濃度 およびゾル成分の平均分子量を 
Table 4 Properties of devulcanized rubber at appropriate condition

\begin{tabular}{l|c}
\hline Mooney viscosity $\left(\mathrm{ML}_{1+4}\right)$ & 36 \\
Gel fraction $(\%)$ & 71 \\
Effective network chain density of & $2.9 \times 10^{-5}$ \\
gel $\left(\mathrm{mol} / \mathrm{cm}^{3}\right)$ & 80000 \\
Average molecular weight of sol & \\
\hline
\end{tabular}

Table 4 に示す．再生ゴムのムーニー粘度は 36 であり，文献 ${ }^{5-7)}$ によるパン法の值とほぼ同等で あった．再生ゴムの網目構造をトルエン溶媒に対 する溶解性と膨潤度から評価したところ，再生ゴ ムの約 7 割は架橋点の残存するゲル成分であり, 膨潤度から見積もられる有効網目鎖濃度は $2.9 \times$

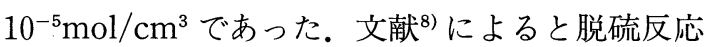
前の試料の有効網目鎖濃度は $2.3 \times 10^{-4} \mathrm{~mol} / \mathrm{cm}^{3}$ であり，仮にこの值と比較すると，脱硫反応処理 によりゲル成分の有効網目鎖濃度は約 $1 / 10$ とな ったと推定される。一方，ゾル成分の平均分子量 は 80,000であった。新材の生ゴムの分子量が明 らかではないので正確な比較はできないが，ゾル 成分の分子量は新材の生ゴムに比べ低下している と考えられる. 次に再生ゴムの加硫特性をキュラ ストメーターを用いて評価した結果を Fig. 1 に 示す. $10 \%$ 加硫時間が 3 分, $90 \%$ 加硫時間が 13 分であった，得られる再加硫ゴムの有効網目鎖濃 度は $2.0 \times 10^{-4} \mathrm{~mol} / \mathrm{cm}^{3}$ であり，脱硫反応前の試 料と比べ若干小さくなっているが, 架橋反応は充 分に進行していると考えられる. 次に再加硫ゴム の応力一Uずみ曲線を Fig. 2 に示す. 最適条件 で得られる再加硫ゴムは引張強さが $12 \mathrm{MPa}$ ，破 断伸びが $340 \%$ であり JIS K6313の規格を満足 した. 文献 ${ }^{5-7)}$ によるとパン法による再加硫ゴム の代表的な力学特性は, 引張強さが $11.5 \mathrm{MPa}$, 伸びが $420 \%$ であり，本手法による再加硫ゴムは 若干伸びは小さいものの，パン法とほぼ同等の力 学特性を有していた。

\section{2 処理温度の影響}

試料にプロセスオイルを添加して，スクリュ回 転数が $200 \mathrm{rpm} の$ 条件で処理温度の影響を検討 した．各処理温度における再生ゴムのムーニー粘 度, ゲル成分量，ゲル成分の有効網目鎖濃度を Table 5 に示す，処理温度が $200^{\circ} \mathrm{C}$ 以下では，得 られる再生ゴムは粉体状で粘度も高く, 脱硫反応

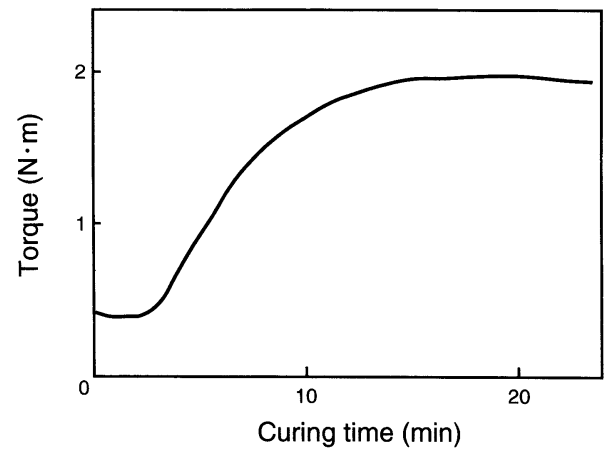

Fig. 1 Curing behavior of devulcanized rubber

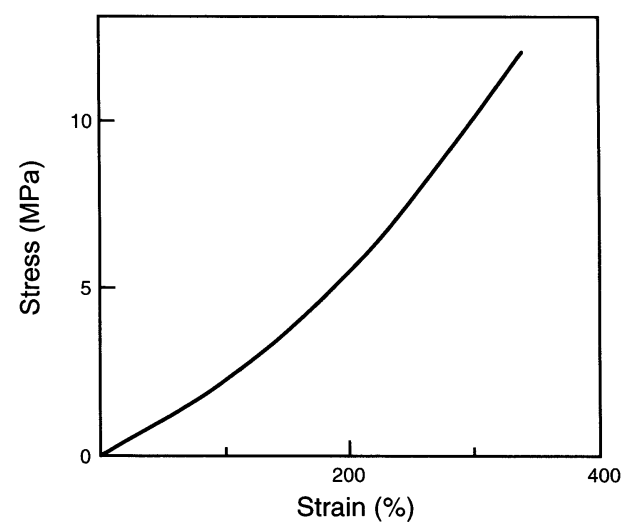

Fig. 2 Stress-strain curve of revulcanized rubber

が不充分であったが， $200^{\circ} \mathrm{C}$ 以上になると脱硫反 応が進行してパン法と同等あるいはそれ以下のム ーニー粘度をもつ再生ゴムを得ることができた。 ムーニ一粘度は処理温度に大きく依存し, 温度の 上昇とともに粘度は低くなった。また，脱硫反応 の指標となるゲル成分量およびゲル成分の有効網 目鎖濃度も処理温度の上昇とともに低下し，処理 温度を上げることにより脱硫反応が促進されるこ とがわかった．ただし，処理温度が $270^{\circ} \mathrm{C}$ 以上に なると, 脱硫反応が進行し過ぎ再生ゴムの粘度, ゲル成分量は非常に低くなった，次に再生ゴムの 加硫特性を加硫時のトルク上昇量と再加硫ゴムの 有効網目鎖濃度により評価した。その結果を Table 6 に示す．処理温度の上昇とともにトルク 上昇量は小さくなり，処理温度が $290^{\circ} \mathrm{C}$ 以上にな るとトルク上昇が認められなかった。また得られ る再加硫ゴムの有効網目鎖濃度は，処理温度の上 
Table 5 Influence of devulcanization temperature for properties of devulcanized rubber

\begin{tabular}{cccc}
\hline $\begin{array}{c}\text { Temperature } \\
\left({ }^{\circ} \mathrm{C}\right)\end{array}$ & $\begin{array}{c}\text { Mooney viscosity } \\
\left(\mathrm{ML}_{\mathbf{1}+4}\right)\end{array}$ & $\begin{array}{c}\text { Gel fraction } \\
(\%)\end{array}$ & $\begin{array}{c}\text { Effective network } \\
\text { chain density of gel } \\
\left(\times 10^{-5} \mathrm{~mol} / \mathrm{cm}^{3}\right)\end{array}$ \\
\hline 200 & 36 & 71 & 2.9 \\
240 & 31 & 69 & 2.6 \\
260 & 25 & 62 & 2.0 \\
280 & 13 & 49 & 2.0 \\
\hline
\end{tabular}

Table 6 Influence of devulcanization temperature for curing properties

\begin{tabular}{ccc}
\hline $\begin{array}{c}\text { Temperature } \\
\left({ }^{\circ} \mathrm{C}\right)\end{array}$ & $\begin{array}{c}\text { Amount of torque } \\
\text { change }(\mathrm{N} \cdot \mathrm{m})\end{array}$ & $\begin{array}{c}\text { Effective network chain } \\
\text { density of revulcanized rubber } \\
\left(\times 10^{-4} \mathrm{~mol} / \mathrm{cm}^{3}\right)\end{array}$ \\
\hline 200 & 1.6 & 2.0 \\
240 & 1.5 & 1.8 \\
260 & 0.9 & 1.6 \\
280 & 0.3 & 1.1 \\
\hline
\end{tabular}

$240^{\circ} \mathrm{C}$ 条件でスクリュ回転数の 影響を検討した．各スクリュ回転 数におけるムーニ一粘度, ゲル成 分量, ゲル成分の有効網目鎖濃度 を Table 7 に示す. 再生ゴムの ムーニ一粘度はスクリュ回転数の 増加とともに低くなった。また， 再生ゴムのゲル成分量, ゲル成分 の有効網目鎖濃度もスクリ工回転 数の増加とともに低くなる傾向に あり，脱硫反応はスクリュ回転数 により促進されることがわかっ た. 再生ゴムの加硫特性をキュラ ストメーターにより評価したとこ ろ，加硫時のトルク上昇量はスク リュ回転数の増加とともに減少し たがその差はわずかであった。ま た， $10 \%$ 加硫時間および $90 \%$ 加 硫時間はいずれの条件でもほぼ同 等であり，加硫特性はスクリュ回 転数にほとんど依存しなかった。次に再加硫ゴム の応力ーUずみ曲線を Fig. 4 に示す。スクリュ 回転数が $100 \sim 200 \mathrm{rpm}$ の範囲では, 破断伸びは ほとんど変化しなかったが，引張強さは回転数が 低いほど高くなった。スクリュ回転数が $400 \mathrm{rpm}$ と高くなると引張強さ，破断伸びともに若干低い 值となった。

再加硫ゴムの力学特性はスクリュ回転数に依存 し，スクリュ回転数の減少とともに引張強さ, 破 断伸びが向上した。スクリュ回転数は $100 \sim 200$ $\mathrm{rpm}$ 前後が適切であった.

\section{4 プロセスオイルの影響}

プロセスオイルの添加の影響を処理温度が $240^{\circ} \mathrm{C}$ ，スクリュ回転数が $100 \mathrm{rpm} の$ 条件で検討 した．プロセスオイルの添加により，再生ゴムの ムーニ一粘度, ゲル成分量, ゲル成分の有効網目 鎖濃度は若干低くなったが，加硫特性にはほとん ど影響を与えなかった. 得られる再加硫ゴムの応 力一Uずみ曲線を Fig. 5 に示す.プロセスオイ ルの添加により, 引張強さはほとんど変化しなか ったが，破断伸びの大きい再加硫ゴムを得ること ができた。

\section{4. 結}

論

せん断流動場反応槽の処理温度，スクリュ回転 
Table 7 Influence of number of screw rotation for properties of devulcanized rubber

\begin{tabular}{cccc}
\hline $\begin{array}{c}\text { Screw rotation } \\
(\mathrm{rpm})\end{array}$ & $\begin{array}{c}\text { Mooney viscosity } \\
\left(\mathrm{ML}_{1+4}\right)\end{array}$ & $\begin{array}{c}\text { Gel fraction } \\
(\%)\end{array}$ & $\begin{array}{c}\text { Effective network } \\
\text { chain density of gel } \\
\left(\times 10^{-5} \mathrm{~mol} / \mathrm{cm}^{3}\right)\end{array}$ \\
\hline 100 & 36 & 71 & 2.9 \\
200 & 31 & 69 & 2.6 \\
400 & 20 & 61 & 2.1 \\
\hline
\end{tabular}

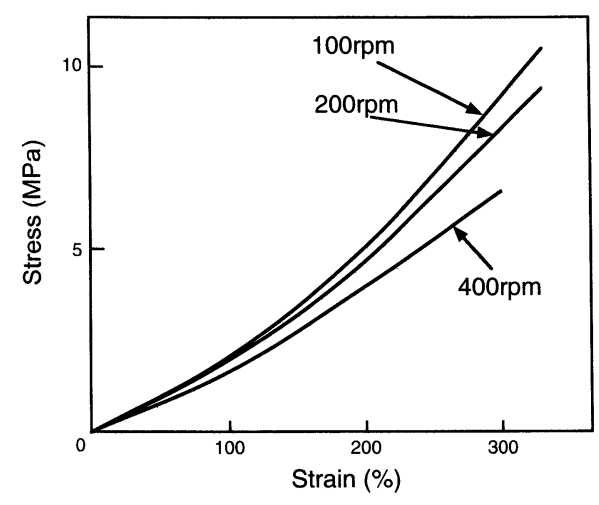

Fig. 4 Influence of number of screw rotation for stress -strain curve

数，プロセスオイルの添加の有無を適切に設定す ることにより，廃夕イヤを連続的に脱硫すること が可能となった．再生ゴムのムーニ一粘度はパン 法とほぼ同等であり，硫黄系の加硫剤により加硫 成形が可能であった，得られる再加硫ゴムの力学 特性は JIS K 6313 の規格を満足し, パン法によ る再加硫ゴムとほぼ同等であった。

\section{参考文 献}

1 ）毛利 誠, 佐藤紀夫，岡本浩孝，松下光正，本多秀 亘，中島克己，竹内勝政，鈴木康之，大脇雅夫：日ゴ 么協誌，72，43(1999)

2 ) 毛利 誠, 佐藤紀夫, 岡本浩孝, 松下光正, 本多秀

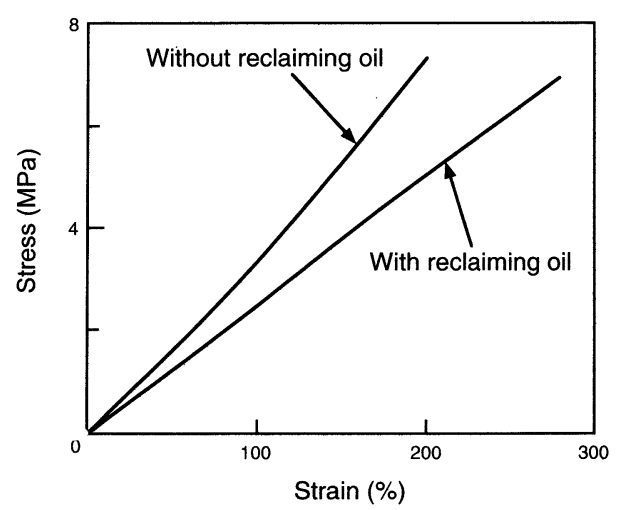

Fig. 5 Influence of process oil for stress-strain curve

亘, 中島克己, 竹内勝政, 鈴木康之, 大脇雅夫 : 日ゴ 厶協誌，72，50(1999)

3 ) 毛利 誠, 佐藤紀夫, 岡本浩孝, 松下光正, 本多秀 亘, 中島克己, 竹内勝政, 鈴木康之, 大脇雅夫：日ゴ 么協誌，72，278(1999)

4 ) 毛利 誠, 佐藤紀夫, 岡本浩孝, 松下光正, 本多秀 亘, 中島克己, 竹内勝政, 鈴木康之, 大脇雅夫 : 日ゴ 厶協誌, 72, 283(1999)

5 ）横田硯二, 門田文夫：日ゴム協誌，66，180(1993)

6 ）川端成涁，山下晋三：日ゴム協誌，49，908(1976)

7 ）古川淳二, 岡本 弘, 稲垣慎二, 尾之内千夫, 案西司 朗, 渡部洋児, 藤田寛治, 柴田慶三：日ゴム協誌, 53，497(1980)

8 ) 古川淳二, 岡本 弘, 稲垣慎二, 尾之内千夫, 案西司 朗, 藤井吉彦, 藤田寬治, 柴田慶三：日ゴム協誌, 53, $490(1980)$ 